\title{
O conceito de Crime e Criminalidade para agentes de segurança da cidade de Curitiba
}

El concepto de crimen y criminalidad para los agentes de seguridad en la ciudad de Curitiba The concept of crime and criminality for agents of security in the city of Curitiba

\section{Camilla Silva Baltazar}

Universidade Positivo, Curitiba, PR, Brasil.

Juliana Fátima Stocki

Universidade Positivo, Curitiba, PR, Brasil.

\section{Roberta Kafrouni}

Universidade Tuiuti do Paraná, Curitiba, PR, Brasil.

\section{Resumo}

O objetivo desta pesquisa foi analisar os significados das palavras "crime" e "criminoso" para os agentes da segurança pública na cidade de Curitiba. Participaram do estudo 16 agentes, todos os participantes tinham grau de escolaridade superior completo. $\mathrm{O}$ instrumento de coleta de dados foi um questionário contendo perguntas abertas e fechadas. As respostas das perguntas fechadas foram organizadas em tabelas. As perguntas abertas foram categorizadas e posteriormente quantificadas. Após a análise dos resultados, foi identificada nas respostas uma tendência dos agentes em culpabilizar o indivíduo, atribuindo valor moralizante ao sujeito tido como criminoso e aos seus atos.

Palavras chave: Crime, Criminoso, Agentes, Segurança Pública.

\section{Resumen}

El objetivo de esta investigación fue analizar los significados de las palabras "delincuencia" y "criminal" de los oficiales de seguridad pública en la ciudad de Curitiba. El estudio incluyó 16 agentes, todos los participantes habían completado un nivel superior de educación. El instrumento de recolección de datos fue un cuestionario con preguntas abiertas y cerradas. Las respuestas de las preguntas cerradas fueron organizadas en tablas. Las preguntas abiertas fueron categorizadas y cuantificadas. Después de analizar los resultados, hemos identificado 
una tendencia en las respuestas de los agentes en culpar la persona, la asignación de valor de la materia que lleva un criminal y sus actos.

Palabras clave: Delincuencia, Criminal, Oficiales, Seguridad pública.

\begin{abstract}
The objective of the present work is to analyze the meaning of words "crime" and "criminal" for public safety agents in Curitiba. Sixteen police agents took part in the research, all being graduated. Data was achieved by means of a questionnaire containing open and multiple choice questions. Multiple choice answers were organized in tables. Answers for open questions were categorized and then quantified. After results analysis, it was identified a tendency in blaming individuals, attributing moralizing value to individuals taken as criminals and their acts.
\end{abstract}

Keywords: Crime, "Criminal”, Agents, Public Safety.

\section{Introdução}

Desde meados da década de 1970, vem-se intensificando, no Brasil, a sensação de medo e insegurança, no entanto, essa sensação não parece infundada. A partir deste período as estatísticas oficiais de criminalidade indicam a aceleração do crescimento de todas as práticas de atividades delituosas. (Adorno, 2002).

A partir dos anos setenta, nos países industrializados, houve um acréscimo de 300 a $400 \%$ nas taxas de criminalidade. A partir dos anos oitenta na América Latina e na Europa Oriental e Ásia Central, as taxas de homicídios aumentaram em mais de $50 \%$ e $100 \%$ respectivamente. (Fajnzylber \& Araújo Jr, 2001).

Segundo Adorno (2002) os crimes que envolvem a prática de violência, como os homicídios, os roubos, os sequestros e os estupros são os que apresentam maiores números de ocorrência. Juntamente com esse aumento nos índices de criminalidade, podem-se observar alterações substantivas nos padrões de criminalidade individual, assim como na descrição das pessoas envolvidas com a criminalidade.

De acordo com Soares (2007) não são fáceis as explicações para a questão da violência e do crime, sendo necessário não se fazer generalizações a seu respeito. Para o autor não existe o crime, no singular. Há vários tipos de práticas criminosas, ligadas a dinâmicas sociais diversas. Dessa 
maneira não é possível identificar uma única causa para o multifacetado mundo da criminalidade.

De acordo com Beato (1998) os sociólogos são familiarizados com duas teorias que se opõem uma à outra, quando se procura uma definição para as causas da criminalidade. A primeira aborda a questão da violência e da criminalidade como fenômenos que se devem, primordialmente, a fatores sociais, tais como: falta de recursos financeiros, privação de oportunidades, desigualdade social e marginalização, que seriam fatores determinantes para a ação criminosa. A segunda teoria atribui ao indivíduo e às práticas criminosas um ataque ao consenso moral e normativo da sociedade; assim, o crime seria produto da prática criminosa de um indivíduo imoral ou amoral. Dessa forma, para restabelecer os principais valores da sociedade, a punição do crime torna-se necessária.

De acordo com Frade (2007) essas duas teorias que abarcam o assunto, cada qual privilegiando um determinado aspecto de toda essa complexidade, podem ser classificadas em:

1) Teorias individualistas - que colocam totalmente sobre o indivíduo o motivo de se cometer um crime, seja por meio de explicações biológicas ou de explicações psicológicas.
2) Teorias sociológicas - nessa abordagem o crime tem uma explicação sociológica, pois ele é dependente do papel do contexto cultural e social em que ocorre.

Ainda de acordo com Frade (2007) há críticas para cada uma das teorias e em nenhuma das duas se encontra uma resposta definitiva, porém atualmente a análise sobre o crime e a criminalidade tende a ser cada vez mais vista sob um olhar sociológico, superando a visão individualista.

Pino (2007) declara que a violência é um tema complexo e exige uma análise aprofundada que contemple os fatores sociais, econômicos e políticos. A violência que está presente no Brasil não veio do nada, e embora a sua causa seja vista sob um enfoque emocional ou moralista por muitos, a causa do aumento da violência e da criminalidade está ligada a nossa história social e econômica, embora ainda sejam ignoradas.

Segundo Adorno (2002) a desigualdade social e a concentração de riquezas, eventos que continuaram presentes no Brasil no decorrer dos anos 90, apesar do crescimento da riqueza e das grandes mudanças ocorridas no cenário econômico, aconteceram simultaneamente à crise fiscal, que outorgou quase exclusivamente ao Estado a diminuição da 
violência por meio do incentivo ao desenvolvimento socioeconômico, da ampliação do mercado de trabalho e da garantia de um mínimo de qualidade de vida para toda a população.

Se a crise econômica interfere na qualidade de vida de grandes populações urbanas, principalmente de seus segmentos empobrecidos, a crise econômica também interfere na capacidade do Estado por em prática as leis e garantir a segurança da sociedade. A crise existente no sistema de justiça criminal é um dos fatores que demonstra essa interferência. Estudos já reconhecem a inabilidade do sistema de justiça criminal - agências policiais, Ministério Público, Tribunais de Justiça e Sistema Penitenciário - em controlar o crime e a violência na vigência do Estado democrático de direito. A taxa de criminalidade aumentou e suas características passaram por mudanças, os aspectos que denunciam os problemas enfrentados pelo poder público no serviço constitucional manifestam-se pela audácia no resgate de presos, pelos motins e rebeliões nas penitenciárias e pela presença de regiões nos grandes centros urbanos onde as normas estabelecidas, por exemplo, pelo tráfico de drogas exerce maior poder do que as leis. (Adorno, 2002).
Segundo Pinheiro (1997) à volta ao constitucionalismo democrático no ano de 1988, que garantia ao povo diversos direitos constitucionais, com o principal propósito de construir um Estado de bemestar para a sociedade e poder limitado do governo, pouco efeito teve na diminuição dessas práticas autoritárias na sociedade. "Hoje em dia, os principais alvos da arbitrariedade policial são os mais vulneráveis e indefesos da sociedade brasileira: o pobre, o trabalhador rural e sindicalista, grupos minoritários, crianças e adolescentes abandonados, muitos vivendo nas ruas" (p. 44) Grande parte dessa violência é produto de uma discriminação arraigada na sociedade contra os de classe social mais baixa e as minorias raciais, que muitas vezes são vítimas de abuso de autoridade e homicídios.

Assim como outros países da América Latina, o Brasil é uma sociedade fundamentada na exclusão, uma democracia sem cidadania. Os efeitos da globalização, juntamente com a crise decorrente de ajustes econômicos, segregam a sociedade, deixando de um lado os ricos e de outros os pobres, como se fossem elementos que, devido à classe social pertencente, não pudessem ser misturados. (Pinheiro, 1997).

Com o afrouxamento dos mecanismos de controle social e nos 
lugares onde a violência é utilizada como um instrumento de legítima defesa é grande o poder que o emprego de atos violentos exerce para a resolução de conflitos. Muitas vezes, porém, a violência é somente a reação de indivíduos normais contra situações opressivas, sejam elas, situações de pobreza, casos de humilhação por causa de desemprego, por abuso da autoridade por parte de policiais ou mesmo por pressões do crime organizado. No Brasil e em outros países pobres, a violência se torna uma característica das relações sociais, evidenciando a carência social que o país enfrenta. (Pinheiro, 1997).

Segundo Pinheiro (1997) o pensamento que as elites têm de que os pobres oferecem perigo é sustentado pelo sistema judiciário que condena e pune os crimes exercidos pelos indivíduos mais pobres de nossa sociedade enquanto os membros das elites passam impunes quando cometem um crime.

De acordo com Pinheiro (1997) práticas criminosas como: a corrupção, os escândalos financeiros, a evasão fiscal e a exploração do trabalho infantil e escravo não são percebidos como ameaças ao status quo. Permitindo a tolerância de atos ilegais das classes dominantes e negando os direitos básicos das classes desprivilegiadas. Diante dessa situação, somente as classes privilegiadas de nossa sociedade (média e alta) desfrutam do controle que a democracia desempenha sobre a ocorrência de práticas violentas nas interações sociais cotidianas. Enquanto para os pobres e carentes "o poder intocável continua a ser a face mais visível do Estado" (p.47)

Para Frade (2007) o exercício do poder se dá de maneira complexa, que pode ser caracterizado por jogos de influência e artimanhas, afirmando que o conhecimento é uma das grandes formas de poder, que o poder não precisa ser exercido de forma bruta.

Cabe então perguntar: Onde se encontra o exercício da polícia? Segundo Beato (2008) da mesma forma que fatores ambientais influenciam de maneira regulatória as circunstâncias dos crimes, o papel exercido pela polícia no cenário urbano não pode ser negado. Isso se deve ao fato de que a fiscalização exercida pela polícia nos espaços urbanos com altos índices de criminalidade dependerá em muito da maneira que a polícia atua nesses ambientes.

Segundo Paixão e Beato (1997) dentro dessa perspectiva, a problemática policial na ordem social democrática é assegurar à população o consenso moral, seja demonstrando que o crime não compensa, por meio da detenção do 
criminoso, seja informando às classes sociais periféricas as regras públicas de comportamento da sociedade democrática - a proscrição do ócio, do vício, do crime e da violência instrumental. Os autores ainda salientam que por outro lado, a própria polícia deve ser um objeto a ser contido, devido ao grande potencial de ameaça oferecido aos cidadãos que, quando no pleno exercício de suas liberdades negativas, entenda-se descumprimento de alguma lei, são repreendidos com abuso de poder por parte dos agentes do Estado na repressão ao crime.

Dentro desse contexto se delineiam dois problemas. O primeiro problema se refere à eficácia na provisão de ordem, justiça e paz, e abrange a concentração de poder simbólico e instrumental na organização policial. O segundo problema se refere ao uso restrito de poder pelos agentes policiais para o estabelecimento da ordem. Dessa forma, o modelo de "ordem sob a lei" estabelece um paradoxo identificado pela análise organizacional: "ordem" entendida como conformidade a padrões estritamente morais enquanto "lei" significa os limites racionais ao estabelecimento de ordem. "Logo, é possível postular a incompatibilidade potencial entre justiça substantiva e justiça formal, retoricamente articulada no modelo" (Paixão \& Beato, 1997, p. 236).
Segundo Soares (2007) outro problema presente nas polícias brasileiras, de um modo geral, é a ineficiência encontrada na prevenção e na repressão qualificada, na investigação e na ausência de confiança pela população. Problemas relacionados à corrupção e ao excesso de violência empregado que extrapolam o aceitável. Estão condicionados a uma gestão racional, não avaliam o próprio desempenho, e também não aceitam o controle e o monitoramento externos. Não há uma organização baseado em conhecimentos para solucionar os problemas que vão enfrentar, sobre a práxis, a definição de metas e prioridades a identificar. Não planejam suas práticas, não corrigem os erros a partir dos dados levantados sobre suas intervenções, ou estes simplesmente são desprezados. O autor segue analisando que as polícias são "máquinas reativas, inerciais e fragmentárias, inscritas num ambiente institucional desarticulado e inorgânico, regido por marcos legais rígidos $\mathrm{e}$ inadequados" (p.100). Os servidores não são devidamente qualificados e reconhecidos e os dados não são adequadamente coletados para ajudar nessa cooperação.

Segundo Paixão e Beato (1997) a atuação policial se posiciona entre a legalidade e a ordem social. Quando os 
mecanismos de controle, tido como naturais na cultura, e internalizados na vida cotidiana dos cidadãos fracassam, faz-se então o uso de modelos coercitivos e repressivos para a manutenção da segurança pública.

Diante do contexto social aqui apresentado referente aos determinantes da criminalidade e do papel assumido pela polícia em nossa sociedade cabe questionar como os próprios policiais compreendem esta questão da criminalidade. Sendo estes os que enfrentam de forma mais imediata e cotidiana este fenômeno, é importante identificar como estes indivíduos o apreendem e o que acreditam enfrentar (a criminalidade) e quem julgam estar envolvidos nesta questão (criminoso).

Os termos "crime" e "criminoso" são certamente polissêmicos. A grande veiculação de informações disseminadas pela mídia a respeito da temática colabora para levar a população a crer que o fenômeno se dá de forma incontrolável, gerando um sentimento de temor e impotência. Segundo Beato (1999) esses efeitos repercutem tanto no imaginário cotidiano das pessoas como nos gastos efetuados com sistemas de segurança e comportamentos defensivos.

Para Pino (2007) os conceitos de crime, violência e agressão são frequentemente associados e usados indistintamente, apesar de terem significados distintos. Segundo o autor "essa prática pode mascarar objetivos de natureza ideológica" (p. 767). O autor prossegue: "crime é um conceito de natureza legal que, em si mesmo, significa apenas um ato de transgressão da lei penal, o que assujeita seu autor a penas legais variáveis segundo as sociedades" (p. 767).

O mesmo autor também observa que a partir do século XIX a tradição jurídica reconhecerá o princípio da responsabilidade criminal o que introduzirá nos códigos penais modernos a ideia de que o grau de responsabilidade criminal pode ser alterado por circunstâncias agravantes e atenuantes. Pino (2007) conclui: "pode-se concluir então que o significado de crimes do mesmo gênero pode ser diferente em cada caso, em razão das circunstancias em que ocorre" (p. 767).

A mera definição jurídica de crime, entretanto, não resolve o problema da variabilidade semântica do termo. Como coloca Frade (2007), geralmente tem-se a percepção internalizada de que crime e criminalidade "estão ligados a uma conduta ou situação que foge do "normal", conceito estatístico que considera o comportamento prevalente" (p. 14). Esta noção trás consigo ainda outro problema, a saber, como se pode definir e identificar os indivíduos desviantes e qual a diferença 
entre desvio de crime. A autora adota a ideia de crime como "esse tipo de conduta desviante, que viola regras estabelecidas por instituições sociais a quem a sociedade, como um todo, atribuiu competência e poder" (Frade, 2007, p. 15).

Pode-se perceber que o crime remete a uma definição constituída e adotada pela sociedade. Também aqueles indicados como criminosos são reconhecidos a partir de critérios definidos socialmente. Com isso queremos dizer que a polissemia dos termos não impede a identificação de alguns significados mais estáveis adotados pelos indivíduos que compõe um determinado grupo social, ainda que estes nem sempre estejam plenamente conscientes destes significados. É possível identificar certa estabilidade na forma como certos termos são definidos pelos indivíduos de um determinado coletivo e como são utilizados. É esta a noção de significado formulada por Vygotsky (1934/1993). Para o autor o significado é uma generalização e, portanto, não se refere a um objeto isolado, mas a uma classe de objetos. O significado designa uma categoria que "por convenção tácita, a sociedade humana considera uma unidade" (p.5). E para Vygotsky estas as convenções tácitas designadas pelas palavras são o que possibilitam a comunicação humana. "As formas mais elevadas da comunicação humana somente são possíveis porque o pensamento do homem reflete uma realidade conceitualizada" (p.5). Com isso não queremos dizer que o significado abrange todas as formas de interpretação que os indivíduos fazem da realidade. Vygotsky indica que a experiência individual não é, a rigor, transmissível, isto é, compartilhamos significados exatamente porque são generalizações. No entanto, os significados permitem o intercâmbio social. Os significados são, portanto, sociais e apontam para o modo como uma determinada realidade é apreendida. Sendo a Psicologia Histórico-Cultural de Vygotsky uma perspectiva essencialmente dialética, devemos acrescentar que, além disso, o significado também aponta aos determinantes concretos desta realidade.

$\mathrm{Na}$ presente pesquisa, dedicamonos a apreender os significados das palavras "crime" e "criminoso" para agentes de segurança pública. Partimos do pressuposto que conhecer tais significados nos permite compreender como tais agentes interpretam $\mathrm{o}$ fenômeno da criminalidade e como se relacionam com ele, sendo estes os indivíduos que estão em contato direto com esta questão. Compreendemos também que os significados não são lineares, mas por revelar certos aspectos da realidade, são 
multideterminados e contraditórios. Além, disso compreendemos que os significados de crime e criminalidade associam-se a outras questões como, por exemplo, a visão de homem e de sociedade dos indivíduos que compartilham esses significados.

\section{Metodologia}

Participaram do estudo 16 agentes da segurança pública da cidade de Curitiba que faziam parte de um grupo de formação de delegados, escrivãos e investigadores. Estes haviam sido aprovados em concurso público para os cargos que exigiam formação universitária.

$\mathrm{O}$ instrumento de coleta de dados foi um questionário com 14 questões. Algumas das questões do questionário eram fechadas, contendo alternativas e outras eram abertas, demandando a redação das respostas. Este formato favoreceu a captação não só de significados, mas das contradições presentes no discurso, uma vez que muitas perguntas abordavam diferentes aspectos de um mesmo assunto. Por exemplo, perguntou-se de forma objetiva quais os motivos que levariam um indivíduo a cometerem um crime e de forma dissertativa quais estratégias poderiam ser praticadas no combate à criminalidade.
A análise das informações contidas nos questionários foi efetuada tanto de forma quantitativa como qualitativa. As respostas às perguntas objetivas foram quantificadas $\mathrm{e}$ as dissertativas foram analisadas por meio do procedimento de codificação aberta (Flick, 2009). Esta forma de análise "tem a finalidade de expressar dados e fenômenos na forma de conceitos" (p. 277). O conteúdo das entrevistas foi organizado, buscando-se unidades de conteúdo, e posteriormente codificado. Também comparamos as respostas às perguntas objetivas $\mathrm{e}$ dissertativas, bem como as respostas dissertativas entre si. Assim, foi possível encontrar as generalizações relativas aos significados de crime e criminoso, assim como os aspectos associados a eles, como a visão de homem e a relação entre sociedade e crime.

\section{Resultados}

Todos os agentes de segurança pública participantes da pesquisa tinham nível de escolaridade Superior Completo. $50 \%$ da amostra, representando 8 participantes, não especificaram o curso de graduação, os outros $50 \%$, representando 8 participantes, cursaram Direito, sendo que destes, 2 participantes além do curso de Direito citaram mais uma graduação 
concluída, um em Administração e outro em Pedagogia.

Foi perguntando aos participantes se em sua opinião o ser humano nascia com características boas, características boas e más, ou características indeterminadas. Podemos visualizar na Figura 1 que a menor prevalência foi de que $o$ ser humano nasce com características boas, seguida de que ao nascerem as características do ser humano são indeterminadas. A característica que apresentou maior prevalência foi que o ser humano nasce com características boas e más (Figura 1).

Todos os participantes, $100 \%$ da amostra, citaram que a sociedade influencia o comportamento humano. As principais respostas que expressam essa influência, são: “o ser humano sofre influência da família”, "por faltar condições básicas para um bom desenvolvimento", “o homem é produto do meio", "a sociedade é determinante na formação dos valores éticos e morais do indivíduo", "a sociedade influencia a personalidade", "padrões estabelecidos pela sociedade".

Pediu-se aos participantes que escrevessem cinco palavras associadas ao termo crime e outras cinco associadas ao termo criminoso. As respostas foram codificadas de acordo com as seguintes definições:

1) Palavras de cunho Moral: referem-se ao conjunto de regras de conduta ou hábitos julgados como aceitos socialmente.

2) Palavras associadas ao Direito Penal: palavras relacionadas à pena judicial ou às leis penais.

3) Palavras com características Emocionais: palavras associadas a situações que mobilizam sentimentos.

4) Palavras relacionadas à Ação Policial: referentes à ação da polícia ou útil aos seus fins.

5) Palavras relacionadas à Ação Judicial: relativas à esfera judiciária.

6) Palavras de cunho Social: referentes a fatores sociais associados à criminalidade.

7) Palavras de cunho Psicológico: referem-se ao conjunto de estados e disposições psíquicas e mentais de um indivíduo.

8) Outros: palavras que não satisfaziam aos critérios anteriores.

A categoria Social foi a que mais enquadrou as palavras associadas ao termo de crime, seguida das seguintes categorias: moral, penal, emocional e ação policial respectivamente.

As categorias moral e social foram as que mais 
enquadraram as palavras associadas ao termo criminoso, seguido das seguintes categorias: psicológico, penal, ação policial e ação judicial respectivamente.

Foi questionado aos participantes se haveria alguma situação em que o crime seria justificável. Para 56\% dos participantes um crime pode ser justificado nos casos de legítima defesa própria ou de outrem, furto famélico e em casos previstos em lei. Para 44\% dos participantes as explicações para crimes não são justificáveis, e mesmo que a justificativa para algum crime seja plausível, ela jamais será aceitável.

Pediu-se aos participantes que indicassem numa escala de 0 a 10 qual seria o grau de responsabilidade do indivíduo por um crime cometido por ele. Pediu-se também que se indicasse o grau de responsabilidade da sociedade. Os resultados podem ser melhor visualizados nas Figuras 2 e 3.

Como podemos observar na Figura 2 é notável que as respostas relativas ao grau de responsabilidade atribuído ao indivíduo concentraram-se nos graus acima de sete. Em contrapartida, na Figura 3 pode-se perceber que as respostas relativas ao grau atribuído a sociedade ficam abaixo de cinco.

Pediu-se que os participantes assinalassem os principais fatores motivadores para uma pessoa cometer um crime entre as categorias: Psicológico, Educacional, Espiritual, Econômico e Outros. Os fatores mais indicados respectivamente foram: Psicológico, Econômico, Educacional, Espiritual e Outros (Figura 4).

Perguntou-se aos participantes qual seria a melhor estratégia para a resolução do problema da criminalidade. A estratégia mais indicada foi a educação com $75 \%$, seguida por distribuição de renda, igualdade de oportunidades, investimento em segurança pública (políticas de prevenção, polícia judiciária, privatização do sistema carcerário, construção de presídios, combate efetivo com penas mais duras), criação de empregos, redução da desigualdade social, confiança na punição, planejamento e reestruturação familiar, conjunto de medidas governamentais, sociais e interdisciplinares, fortalecimento na formação da personalidade, ressocialização dos presos e controle de natalidade.

Uma das questões do instrumento solicitava ao participante que ordenasse os crimes conforme o a gravidade, numa escala que variava de 1 a 5 , sendo 1 o menos grave e 5 o mais grave. Deixou-se que o participante citasse livremente os crimes (tabela 1). 
Como podemos visualizar na tabela 1 os crimes contra a vida foram os que apresentaram maior índice de gravidade no grau 5, seguidos de crimes contra a dignidade sexual, crimes contra o patrimônio, crimes de ordem pública e crimes de ordem economia. Fazendo a mesma análise com o nível de gravidade 4, os crimes contra a vida continuam com o maior número de indicações, seguidos dos crimes contra o patrimônio, crimes de ordem pública, crimes contra a dignidade sexual e crime de ordem econômica respectivamente.

Por fim, perguntou-se aos participantes se uma pessoa deixava de ser criminosa após o cumprimento da pena. Solicitou-se que os participantes justificassem suas respostas. Para $68 \%$ dos participantes, após o cumprimento da pena a pessoa não deixa de ser criminosa, sob a justificativa de que a sentença não ressocializa, aumenta a agressividade do indivíduo, a pena não reeduca e não proporciona reflexão ou revisão da conduta. Para 20\%, após o pagamento da sentença estipulada para o indivíduo, ele deixa de ser criminoso. Para 12\%, após o cumprimento da pena, a pessoa pode ou não deixar de ser criminosa dependendo do contexto em que ela vive que poderá favorecer a reinserção do indivíduo na sociedade ou propiciar condições para a reincidência no crime.

\section{Discussão}

A resposta que apresentou maior prevalência foi que o ser humano nasce com características boas e más. Com isso, entende-se que os entrevistados atribuem aos indivíduos um conjunto de traços decorrentes de uma suposta natureza humana, anterior a experiência social deste, sendo que o indivíduo não se apresenta como uma "tabula rasa". Percebe-se aqui o predomínio de uma visão individualista de ser humano, que coloca sobre o indivíduo o motivo de se cometer um crime, seja através de explicações biológicas ou de explicações psicológicas. Assim sendo, é propicio pensarmos que para os entrevistados a criminalidade é entendida como parte da natureza das pessoas que cometem crimes. Se seguirmos este raciocínio caberia questionar como os policiais entrevistados compreendem sua função, pois se o crime faz parte de uma suposta natureza, a única alternativa que restaria para o combate da criminalidade seria retirar os "desviantes" de circulação.

Esse dado entra em discordância com fato de que $100 \%$ da amostra afirma que a sociedade influencia o 
comportamento humano. Os dados privilegiam, portanto, diferentes teorias para a explicação da criminalidade, o primeiro conjunto de respostas, como já assinalado enfatiza as Teorias individualistas e o segundo enfatiza as Teorias sociológicas, que de acordo com Frade (2007) afirmam o papel do contexto cultural e social na determinação da criminalidade.

Desse modo verifica-se que há contradição na própria percepção dos agentes da segurança pública no que se refere às causas da criminalidade: ora atribui-se à natureza dos criminosos, ora às condições presentes na sociedade que favoreceriam o surgimento de atos criminosos. As duas posições, entretanto, mostram-se perigosas, uma vez que podem conduzir a atitudes preconceituosas que identificam a criminalidade com uma classe social específica. Além disso, a criminalidade passa a ser naturalizada nesta mesma classe social.

\section{Encontramos}

diferentes

significados nas palavras mais associadas ao conceito de crime e criminoso. Nas palavras associadas ao conceito de crime, em primeiro lugar são associadas palavras que enfatizam aspectos sociais, seguido de palavras de aspecto moral. Nas palavras associadas ao conceito de criminoso, em primeiro lugar aparecem palavras de cunho moral. Parece haver uma dicotomia social/individual quando a questão do criminoso e da criminalidade é abordada: quando a questão é posta em termos mais gerais, representados aqui pela palavra crime, as explicações são mais sociais, ao passo que quando se enfocam os indivíduos que cometem crimes o aspecto moral passa a aparecer com maior força. Desta forma, parece que na medida em que se enfoca o indivíduo que cometeu um crime, este é julgado moralmente, o que abre a questão para como se sentem os policiais em relação às pessoas em conflito com a lei e que tipo de tratamento julgam merecerem.

Apesar desta polarização entre indivíduo e sociedade um aprofundamento das questões parece indicar para que lado desta oposição as respostas tendem. Quando perguntados sobre o grau de responsabilidade da sociedade e dos indivíduos em relação ao crime, novamente o indivíduo é responsabilizado pelo crime. $\mathrm{O}$ foco individualista é novamente ressaltado em relação aos fatores sociais quando consideramos $\mathrm{o}$ principal fator motivador para uma pessoa cometer um crime, conforme assinalado nas entrevistas: o fator psicológico aparece com maior frequência. Pode-se perceber que o significado de crime e criminalidade historicamente construído permanece, isto 
é, a culpabilização do sujeito, sem a avaliação dos aspectos sociais, econômicos e políticos que contribuem para a ocorrência de uma prática criminosa.

Apesar da tendência individualista na explicação da criminalidade, quando os pesquisados citam a melhor estratégia para a resolução do problema da criminalidade, esta é pensada a partir de uma ação sobre as condições sociais: a maioria dos participantes aponta a educação com $75 \%$, seguida pelas estratégias de distribuição de renda, igualdade de oportunidades, investimento em segurança pública (políticas de prevenção, polícia judiciária, privatização do sistema carcerário, construção de presídios, combate efetivo com penas mais duras), criação de empregos, redução da desigualdade social, confiança na punição, planejamento e reestruturação familiar, ressocialização dos presos e controle de natalidade.

É recorrente no discurso dos pesquisados a presença dessas contradições. Aqui novamente as implicações dessas contradições podem indicar a criminalização da classe pobre. A educação aparece como a principal forma de enfrentamento do problema da criminalidade. A implicação lógica desta afirmação é que, na perspectiva dos entrevistados, os indivíduos que cometem crimes são em sua maioria sujeitos não educados. A segunda estratégia mais citada é a redistribuição de renda, o que reforça a ideia de que os entrevistados identificam como criminosos os grupos mais desfavorecidos da sociedade: a população pobre e iletrada.

Outra contradição revela a limitada perspectiva de enfrentamento da criminalidade revelada pelos agentes de segurança pública pesquisados. Quando é citada como uma das estratégias para a resolução da violência o aumento no número de penitenciárias. Estes mesmos agentes afirmam que o encarceramento não é eficaz para a ressocialização dos indivíduos tido como criminosos. Para $68 \%$ dos participantes, após o cumprimento da pena a pessoa não deixa de ser criminosa, sob a justificativa de que a sentença não ressocializa, mas aumenta a agressividade do indivíduo, a pena não reeduca e não proporciona reflexão ou revisão da conduta. Para $20 \%$, após o pagamento da sentença estipulada para o indivíduo, ele deixa de ser criminoso. Para $12 \%$, após o cumprimento da pena, a pessoa pode ou não deixar de ser criminosa, dependendo do contexto em que vive, que poderá favorecer ou não a reinserção do indivíduo na sociedade ou propiciar condições para fazê-la reincidir no crime. 
Analisando esses dados, podemos perceber que o indivíduo que cometeu um crime fica marcado na perspectiva dos entrevistados, recebendo um rótulo que carregará permanentemente. Isto pode indicar uma cisão na maneira como os entrevistados encaram sua própria ocupação. Se uma das principais tarefas desses profissionais é levar os criminosos à detenção e se esta não socializa, nem educa, até mesmo favorece o aumento da conduta criminosa, qual a função dos agentes de segurança pública? Seu trabalho perde o sentido. Mais uma vez aqui aparece a criminalidade como um problema insolúvel que só pode ser contido o que levaria a considerar que o papel da polícia, nesta visão, não seria o combate à criminalidade, mas apenas sua contenção. Este aspecto: o sentido atribuído aos agentes de segurança pública ao seu trabalho é certamente um tópico que merece aprofundamento.

Segundo Beinstein (citado por Santos, 2001) o sistema capitalista promove a exclusão e culpabiliza o próprio excluído. Essa dinâmica é sustentada pela ideologia dominante que sustenta que todos têm as mesmas igualdades de oportunidades, portanto, se alguma pessoa transgride a lei é por vontade própria. Assim, não é surpreendente a visão moralista do criminoso apresentada pelos policiais. A ideologia, segundo Chauí (2001) dissimula a realidade e a mostra sob outro ponto de vista. Desse modo, um conjunto de ideias, imagens e valores são criados para justificar a realidade social em que os indivíduos se encontram, permitindo a conformidade com as condições sociais, não as analisando e as tendo como naturais e justas, impedindo o conhecimento das reais condições sociais em jogo e até mesmo a sua transformação.

Os dados coletados colaboram ao confirmar que a visão de criminoso elaborada por Agentes da Segurança Pública da cidade de Curitiba enfatiza uma visão que criminaliza o indivíduo, sobretudo o indivíduo pobre e iletrado, perpetuando a discriminação da população.

\section{Considerações Finais}

A análise das entrevistas realizadas nesta pesquisa revelou que os significados das palavras "crime" e "criminoso" para os agentes da segurança pública na cidade de Curitiba estão voltados para a culpabilização do indivíduo, isto é, atribuise um valor moralizante ao sujeito tido como criminoso.

A aparente contradição existente na atribuição das causas da criminalidade e as estratégias para seu enfrentamento revela 
um processo de estigmatização das classes pobres.

Cabe aqui uma reflexão sobre o papel que a repressão de fato exerce em nossa sociedade. $\mathrm{O}$ senso comum enfatiza que "bandido bom é bandido preso", uma variante do ditado frequentemente veiculada é que "bandido bom é bandido morto. Esta noção parece estar presente nos significados atribuídos pelos policiais ao criminoso.

Se a própria polícia considera que a pena não socializa, tal questão se estende à sua própria atuação profissional. Se sua atuação é a primeira a exercer uma contenção da criminalidade, e se tal exercício é ineficaz a longo prazo, os policiais parecem estar condenados como
Sísifo a rolar um enorme peso montanha acima só para vê-la rolar para baixo por uma "força irresistível".

O significado de criminoso formulado por Agentes da Segurança Pública atribui uma conotação individual e moralizante, negando toda a estrutura social determinante das práticas criminosas. A manutenção deste olhar ideológico deixa pouca saída para o trabalho dos policiais e à população continuará sendo oferecido "mais do mesmo", ou seja, práticas ineficazes continuarão sendo propostas e aceitas, visando apenas à retirada dos ditos criminosos de circulação.

\section{Tabelas e Figuras}

Figura 1

\section{Características do ser humano ao nascer}

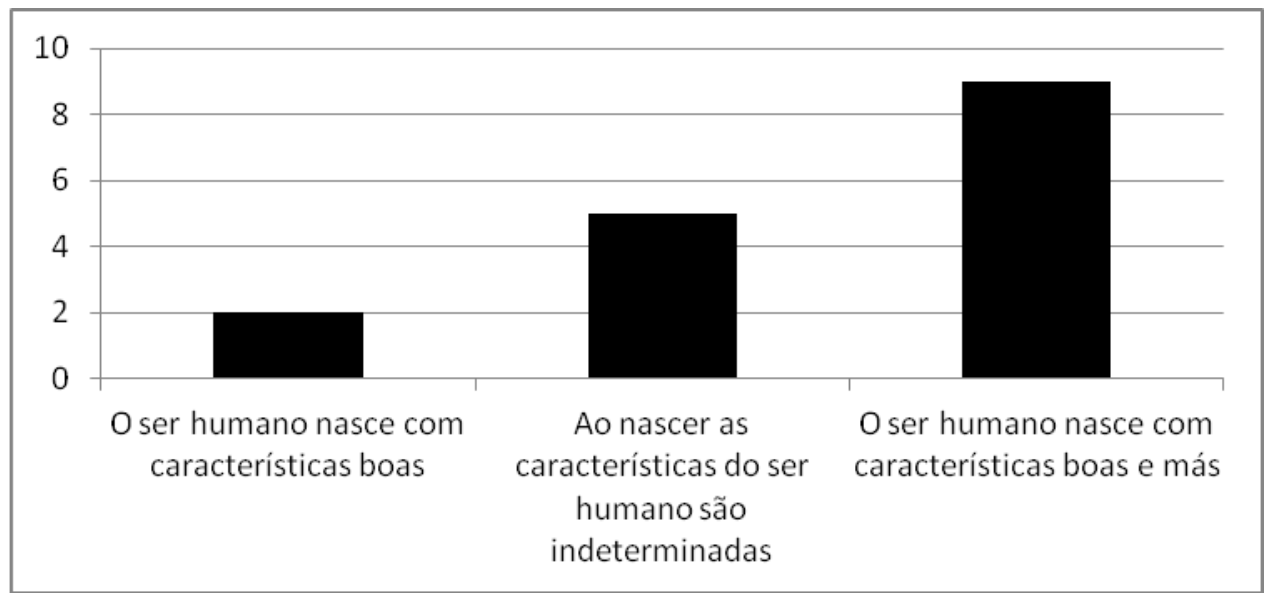


Figura 2

Grau de responsabilidade de um indivíduo que cometeu um crime

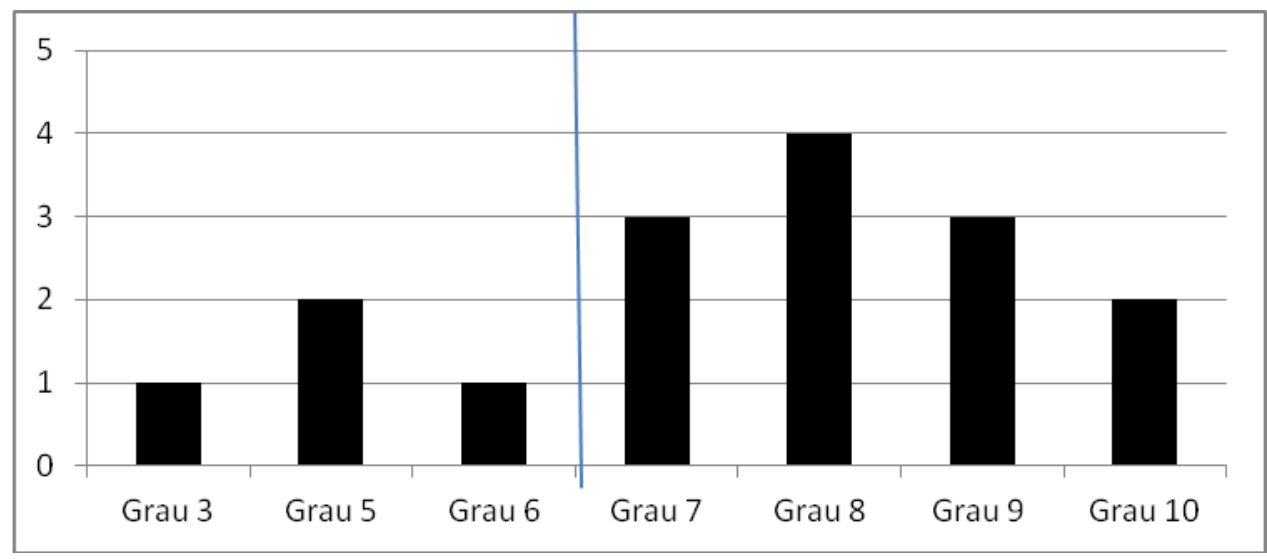

Figura 3

Grau de responsabilidade da sociedade frente a um indivíduo que cometeu um crime

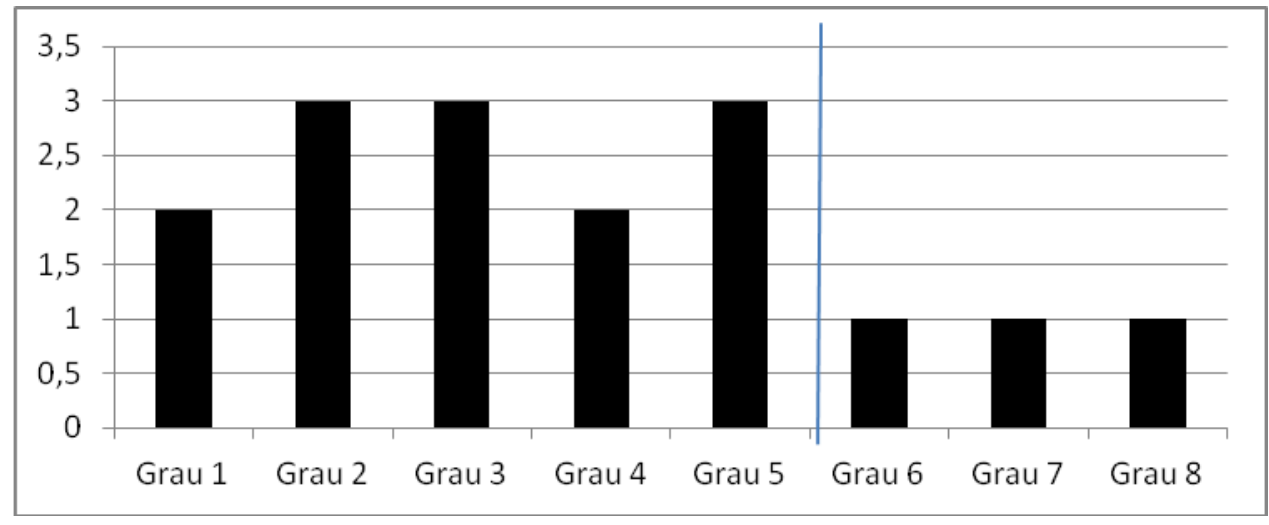


Figura 4

Fatores que motivariam uma pessoa a cometer um crime

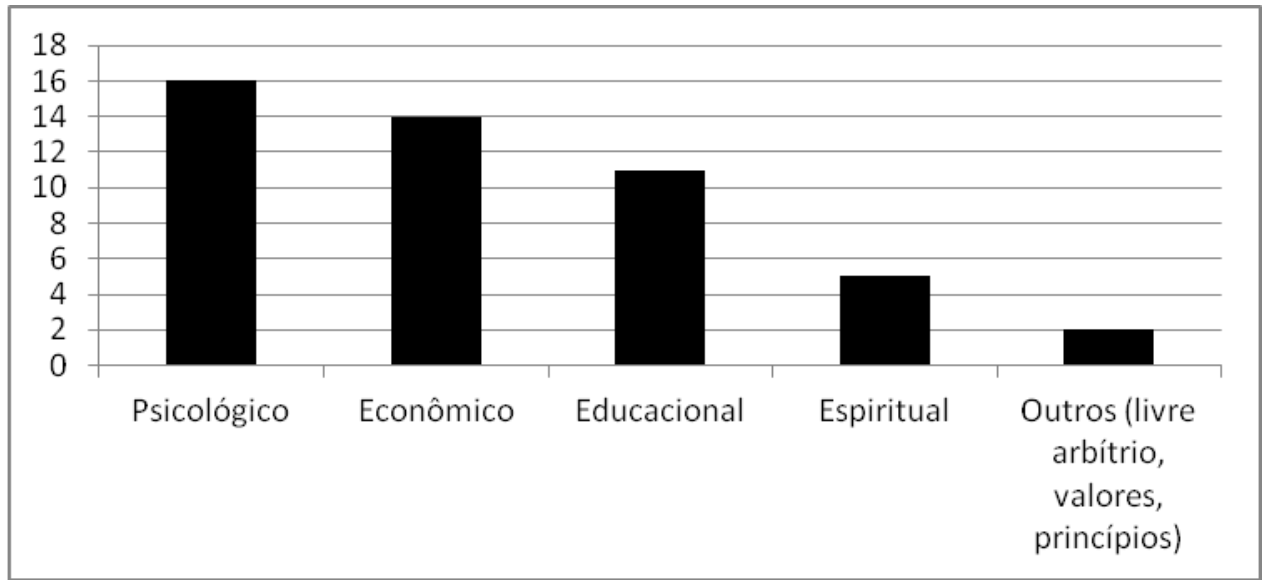

Tabela 1

Representação dos níveis de gravidade dos crimes

\begin{tabular}{|l|l|l|l|l|l|c|}
\hline & Grau 1 & Grau 2 & Grau 3 & Grau 4 & Grau 5 & Total de citações \\
\hline $\begin{array}{l}\text { Crime contra o } \\
\text { patrimônio }\end{array}$ & 04 & 12 & 13 & 08 & 09 & 46 \\
\hline Crime contra a honra & 02 & 07 & 00 & 01 & 00 & 10 \\
\hline Crime de ordem pública & 03 & 02 & 2 & 5 & 05 & 17 \\
\hline Crime contra a vida & 07 & 07 & 05 & 10 & 17 & 46 \\
\hline $\begin{array}{l}\text { Crime contra a dignidade } \\
\text { sexual }\end{array}$ & 01 & 00 & 01 & 02 & 10 & 14 \\
\hline $\begin{array}{l}\text { Crime de ordem } \\
\text { Econômica }\end{array}$ & 00 & 01 & 01 & 02 & 01 & 5 \\
\hline $\begin{array}{l}\text { Crime contra a igualdade } \\
\text { entre etnias }\end{array}$ & 01 & 01 & 01 & 00 & 00 & 3 \\
\hline $\begin{array}{l}\text { Crime de ordem } \\
\text { tributária }\end{array}$ & 00 & 00 & 00 & 01 & 00 & 1 \\
\hline Outros & 04 & 00 & 01 & 00 & 01 & 6 \\
\hline
\end{tabular}




\section{Referências}

Adorno, S. (2002). Crime e violência na sociedade brasileira contemporânea. Jornal de Psicologia-PSI, Abril/Junho, p. 7-8.

Beato, C. F. C. (1998). Determinantes da criminalidade em Minas Gerais. Revista Brasileira de Ciências Sociais, 13(37).

Beato, C. F. C. (1999). Políticas públicas de segurança e a questão policial. São Paulo em Perspectiva, 13(4).

Beato, C. F. C.; Silva, B. F. A.; Tavares, R. (2008). Crime e estratégias de policiamento em espaços urbanos. Dados - Revista de Ciências Sociais, 51(3), p. 687-717.

Chauí, M. S. (2001). Convite à filosofia. 12. ed. São Paulo: Ática.

Fajnzylbe, P; Araújo, A. Jr. (2001). Violência e Criminalidade. Centro de Desenvolvimento Planejamento Regional. Acessado em 07 de maio de 2011 de http://www.ppge.ufrgs.br/direitoeconomia/disciplinas/10/fajnzylberaraujojr-2001.pdf.

Flick, W. (2009). Introdução à pesquisa qualitativa. Porto Alegre: Artmed.

Frade, L. (2007). O que o congresso nacional Brasileiro pensa sobre criminalidade. Tese de Doutorado, UnB , Brasília, Brasil.

Paixão, A. L.; \& Beato, C. F. C. (1997). Crimes, vítimas e policiais. Tempo Social: Revista de Sociologia USP, 9(1), p. 233-248.

Pinheiro, P. S. (1997). Violência, crime e sistemas policiais em países de novas democracias. Tempo Social: Revista de Sociologia USP, 9(1), p. 43-52.

Pino, A. (2007). Violência, educação e sociedade: um olhar sobre o Brasil contemporâneo. Educação e Sociedade, 28(100), p. 763-785.

Santos, T. S. (2001). Globalização e exclusão: a dialética da mundialização do capital. Sociologias, (6), p. 170-198.

Soares, L. E. (2007). A Política Nacional de Segurança Pública: histórico, dilemas e perspectivas. Estudos Avançados, 21(61), p. 77-97.

Vygostky, L.S. (1934/1993). Pensamento e Linguagem. São Paulo: Martins Fontes. 
Juliana Fátima Stocki. Universidade Positivo.

E-mail: ju-stocki@hotmail.com

Camila Baltazar Silva. Universidade Positivo. Graduanda em Psicologia.

E-mail: miilasb@yahoo.com.br
Roberta Kafrouni. Doutorado em Psicologia Social pela Pontifícia Universidade Católica de São Paulo, Brasil (2009). Professor Adjunto da Universidade Tuiuti do Paraná, Brasil.

E-mail: rkbeta@hotmail.com 